https://artnodes.uoc.edu

\title{
La máquina iconoclasta en la era digital
}

\section{José María de Luelmo Jareño}

Universitat Politècnica de València

Fecha de presentación: marzo de 2021

Fecha de aceptación: mayo de 2021

Fecha de publicación: julio de 2021

\section{Cita recomendada}

De Luelmo Jareño, José María. 2021. «La máquina iconoclasta en la era digital». Artnodes, n. ${ }^{0} 28: 1-11$ UOC. [Fecha de consulta: dd/mm/aa]. http://doi.org/10.7238/a.v0i28.385081 \footnotetext{
(C) Los textos publicados en esta revista están sujetos -si no se indica lo contrario- a una licencia de https://creativecommons.org/licenses/by/4.0/deed.es_ES.
}

\section{Resumen}

Ciertos episodios acaecidos a mediados de 2020 sirvieron para constatar la pervivencia de la violencia simbólica de carácter popular. Aunque la afinidad de esas acciones con otros episodios históricos muestra un patrón recurrente, casi de manual, lo cierto es que coinciden en el tiempo con la dinámica de las imágenes característica de la era digital, tácitamente iconoclasta, y con prácticas actuales que también lo son de forma destacada. A la vista de este fenómeno global, el presente artículo se sirve del concepto operativo de máquina iconoclasta para reunir casos dispares y descubrir en ellos un sustrato común que permite establecer insólitas concomitancias dentro de la iconocracia vigente. De especial importancia en el desarrollo de la propuesta son aquellos usos artísticos que renuevan el espíritu de la praxis vanguardista y se sirven de las variables fundamentales de la mecánica iconoclasta para sondear críticamente los atributos de las imágenes contemporáneas.

\section{Palabras clave}

iconoclasia, cultura digital, arte digital, browser art, meme 


\title{
The iconoclastic machine in the digital era
}

\begin{abstract}
Certain episodes which occurred in the middle of 2020 served to confirm the prevalence of symbolic violence of popular character. Although affinity with actions with other historic episodes shows a recurrent pattern, almost manually, what is certain is that they coincide in time with the dynamics of the characteristic images of the digital era, tacitly iconoclastic, and with actual practices which are also it in a highlighted way. In view of this global phenomenon, the article serves itself of the operative concept of the iconoclastic machine in order to reunite different cases and discover in them a common substratum which allows the establishment of the unusual concomitances within the prevailing iconacracy. Of special importance in the development of the proposal are the artistic uses which renew the spirit of the vanguardist praxis and which are served by the fundamental variables of the iconoclastic mechanics in order to critically sound out the attributes of contemporary images.
\end{abstract}

\section{Keywords \\ iconoclasm, digital culture, digital art, browser art, meme}

\section{Introducción}

Sumando su indignación a la tragedia general, a comienzos de junio de 2020 millones de estadounidenses convinieron en que no podían respirar y se echaron a las calles exigiendo la erradicación definitiva del segregacionismo racial. Las airadas reacciones a la muerte del ciudadano George Floyd a manos de la policía, y con ellas las últimas palabras que pronunciase en vida, I can't breathe, fueron elevando el tono día a día. Por todas partes las protestas venían acompañadas de acciones colectivas contra símbolos segregacionistas a cuya conclusión, haciendo buena la expresión, no quedaba títere con cabeza (figura 1), y aunque para muchos esta oleada destructora resultaba sorprendente en pleno siglo XXI, un detenido examen del fenómeno permite situarlo en un marco

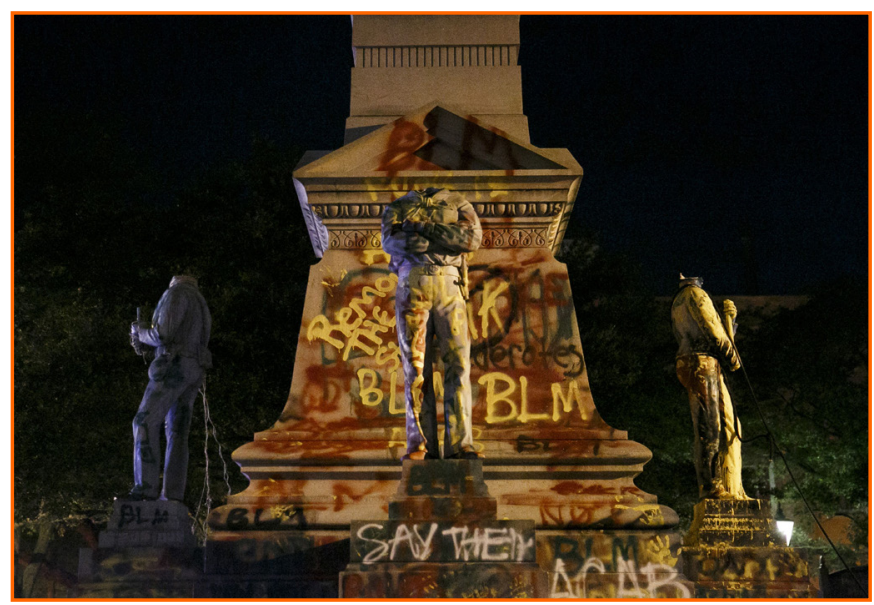

Figura 1. Portsmouth, Virginia, EE.UU. 10 de junio de 2020 histórico donde la violencia simbólica sigue siendo recurrente y la iconoclasia impregna un sinfín de rutinas, especialmente en el entorno digital. El concepto de máquina iconoclasta, libremente inspirado en la obra del antropólogo Furio Jesi, aspira a reunir, articular y sustentar esa casuística dispersa.

Estudioso del mito en todas sus formas, Jesi acuñó a comienzos de los años 70 la noción de máquina mitológica con el fin de situar la actividad mitopoiética del ser humano, un inmenso caudal que se extiende por épocas y civilizaciones muy variadas, al amparo de un mismo principio y de una dinámica común. Si bien «para el intérprete moderno es difícil abandonar su idea de máquina y hacer suyo el contenido representacional, mucho menos específico, de la vieja palabra» (Blumenberg 2003, 142-143), es justamente ese valor metafórico e indeterminado de lo maquinal el que, a efectos metodológicos, interesa a Furio Jesi. El propio antropólogo italiano reconocía haber ideado su máquina mitológica como «un modelo gnoseológico provisionalmente útil» (Jesi 1976, 138) que le permitiera fijar las constantes de una práctica cultural oscilante y heterogénea por definición, y caso de haber continuado con esta pauta y de haberse centrado en la actividad específicamente imaginal del ser humano, es bastante plausible que hubiese forjado la noción de máquina icónica -nada afín a la máquina de visión de Virilio, por lo demás- para asistirle a la hora de reunir todo impulso visual, fuera el que fuera y surgiese donde surgiese, en torno a un mismo embrión.

Acogiéndose a ese supuesto, el concepto de máquina iconoclasta viene a proponerse como un modelo epistémico, accesorio del anterior, donde concurran todas aquellas operaciones que conciben la imagen no como un producto finalista sino como un apriorismo sujeto a destrucción, desgaste, alteración o bloqueo, 


\section{artnodes}

https://artnodes.uoc.edu

La máquina iconoclasta en la era digital

y ello a menudo con intenciones más creativas que lesivas. Con esta premisa, este artículo comienza retomando el caso que servía de preámbulo para fijar el fundamento de la iconoclasia tradicional y prosigue espigando ejemplos de un corpus contemporáneo que debe tanto a las maneras del arte digital como a las gestadas al calor de la sociedad-red. El análisis de esta pluralidad permite entrever los principios operativos de la máquina iconoclasta en el mundo actual atendiendo -en cierto modo como en una máquina real- a la energía que la abastece, a su mecánica interna y a su capacidad productiva, y pulsar de paso su utilidad para estudiar la iconosfera actual desde una perspectiva complementaria a las habituales. Sostiene Bal que «los conceptos pueden provocar y facilitar la reflexión y el debate a todos los niveles metodológicos en las humanidades» $(2009,44)$, y esa y no otra es la intención que persigue la noción experimental de máquina iconoclasta.

\section{De lo social salvaje ${ }^{1}$ a la iconoclasia digital}

Que el arrebato colectivo de mediados de 2020 respondía a un esquema estandarizado lo evidencia el hecho de que Elias Canetti Io hubiera ya fijado en su obra canónica Masa y poder:

"La destrucción de imágenes que representan algo es la destrucción de una jerarquía que ya no se reconoce [...]. La expresión de su permanencia era su dureza; han existido desde hace mucho tiempo, desde siempre, según se cree, erguidas e inamovibles, y era imposible aproximarse a ellas con intención hostil. Ahora están caídas y quedaron hechas escombros.» $(1983,14)$

Se agrede a esas imágenes porque se alberga la esperanza de promover con ello un giro en la gramática social, y de hecho sucede que este tipo de eventos se convierte a menudo en «lo que reúne, lo que quiebra la atomización, lo que funda la creación colectiva» (Maffesoli 2012, 64). En el caso específico de la crisis iconoclasta de 2020, la secuencia de acontecimientos nos dice que la denuncia de aquel caso de abuso racial específico habría dado paso a la del abuso racial sistémico y acto seguido a la del abuso racial histórico, sin solución de continuidad, y nos dice también que en cada una de esas etapas las imágenes habrían propiciado rituales paganos donde personas de toda condición evidenciaban su repulsa arremetiendo contra símbolos inertes que, a juzgar por el valor que se les adjudicaba, parecían no serlo. Efectivamente, al estudiar el modus operandi de las huestes iconoclastas «queda patente que un gran número de ataques contra imágenes -si no la mayoría- se basa de un modo u otro en la atribución de vida a la figura representada o en la suposición correspondiente de que el signo es de hecho el significado» (Freedberg 2014, 461) 0, por decirlo con Gadamer, sucede en estos casos que «la imagen no se agota en su función de remitir a otra cosa, sino que participa de algún modo en el ser propio de lo que representa» $(2001,204)$ y se hace por ello acreedora de un carácter apotropaico que invita a la ejecución en efigie del referente.

Que la imagen cumple como figura interpuesta en este tipo de fricciones sociales lo demuestra una secuela espuria y a menudo complementaria -el caso anterior fue buena evidencia (figura 2)- de la iconoclasia performativa: el meme. Aunque haya quien sostenga que «un meme de Internet es un elemento cultural, habitualmente una broma, que gana influencia a través de su transmisión en línea» (Davison 2012, 122), lo cierto es que no tiene por qué poseer una intención burlesca y a menudo ni siquiera alcanza repercusión, de modo que tal vez sea más oportuno caracterizarlo genéricamente por su capacidad de violentar la imagen original que le sirve como soporte. A efectos teóricos ese es justamente el factor que aquí interesa, la calidad de esa acción, porque nos sitúa en la estela de cierta iconoclasia ancestral que opera mediante una tergiversación del estatuto de la imagen, de su integridad física o de su sentido original.

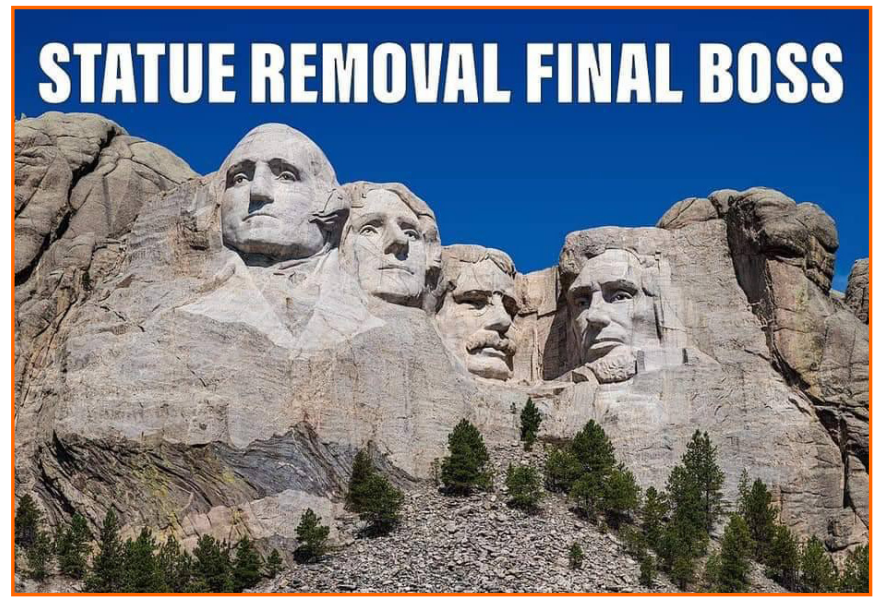

Figura 2. Meme en circulación a mediados de 2020

De entrada, cabe observar que la noción de máquina iconoclasta posee en el caso del meme una doble dimensión operativa: como ars combinatoria de materiales heterogéneos, por un lado, y como mecánica productiva abierta a la pura contingencia, por el otro. El primer sentido atañe a la imagen macro (macro image) que resulta de combinar cierto motivo visual con determinado lema sin que entre ambos exista, en principio, una relación de contigüidad, a tal punto que una misma imagen puede servir de anclaje a varios enunciados y un mismo texto acoplarse a imágenes diversas. Cualquiera que sea

1. La expresión se debe al antropólogo Manuel Delgado (2001, 21). 


\section{artnodes}

el caso, la clave reside en forzar la imagen para que diga aquello que por sí sola no es capaz de decir o diga algo distinto a lo que de suyo está diciendo, una artimaña vanguardista, la del desvío 0 detournément, que renueva fuerzas gracias a la desenvoltura con la que puede ahora llevarse a efecto. La popularización de herramientas de bricolaje digital facilita la incorporación de texto a una imagen preexistente -algo que venía haciéndose al menos desde L.H.O.O.Q. de Marcel Duchamp (1919, figura 3) y llega, a través de obras como The avantgarde doesn't give up de Asger Jorn (1962, figura 4), a los movimientos Adbusters o Billboard Liberation Movement- sin que ello impida que vayan instaurándose de forma tácita ciertos estándares relativos a la composición, las relaciones de aspecto 0 la utilización de determinadas tipografías -la Impact, sobre todo. Ciertamente, «los sistemas meméticos se definen por la presencia de un meme emergente (una forma alterada de medios de difusión) que se reproduce recursivamente en un proceso en el que los agentes

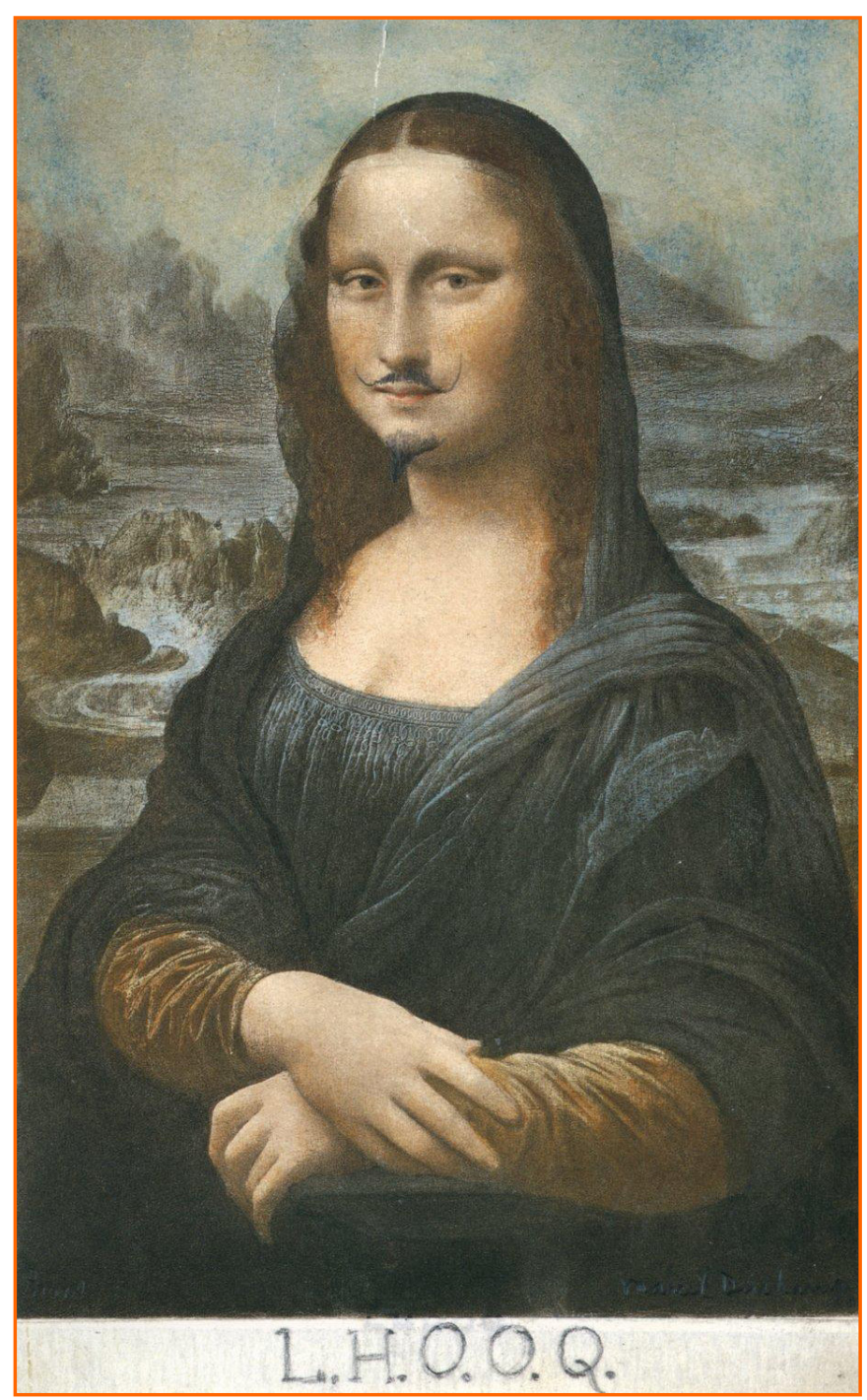

Figura 3. Marcel Duchamp. LHOOQ. 1919

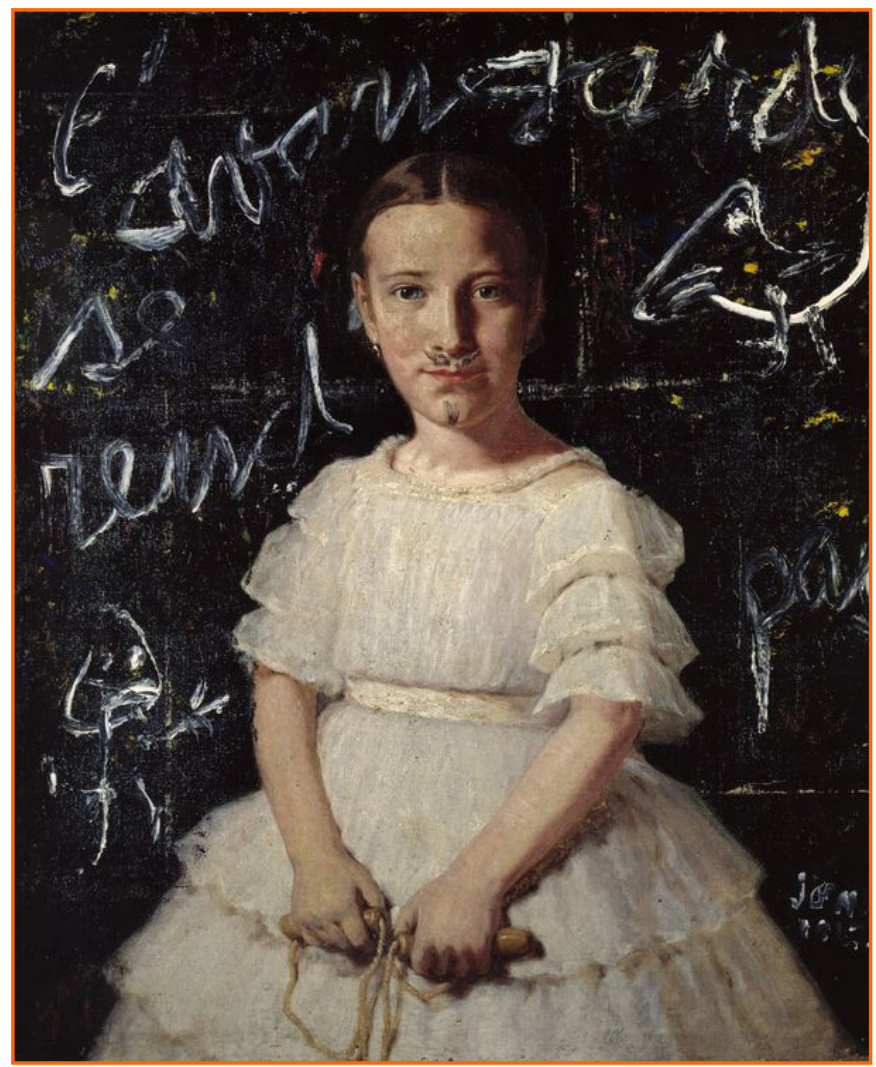

Figura 4. Asger Jorn. The avantgarde doesn't give up. 1962

se adhieren a una estructura no declarada pero conocida» (Wiggins y Bowers 2015, 1901), y ese patrón recursivo viene dado en buena medida por las viejas leyes del isomorfismo o la pregnancia y por la normalización visual.

La pérdida de experimentalidad que esto comporta queda compensada por la otra dimensión operativa del meme, la de ser un producto abierto a una constante mutabilidad que hace tan impredecible su iteración como el eco que pueda llegar a alcanzar. Este potencial metamórfico, que se halla en la base del propio término meme (Dawkins 1976), da pie a un seudoarte generativo que a menudo sería más oportuno calificar como degenerativo a juzgar por el desgaste ético al que su lógica difusa, sostenida como está en la hipérbole, el afán polémico, la desregulación y el anonimato, puede incitar. Que el meme sea capaz de actuar como vehículo de un linchamiento simbólico popular se ve potenciado por el hecho de que la comunidad de usuarios convierte la teatralización a pie de calle en una rutina doméstica y la furia corporal en la gestión de una interfaz donde ni la integridad física ni la legal están en juego. Se violenta la imagen digital y aquello que representa porque es una acción simple y eficaz en cualquier contexto, de la represión política en Marruecos a la del colectivo gay en Rusia y del independentismo catalán al propio conflicto racial en Estados Unidos (Moreno-Almeida 2020; Baker et al. 2020; Algaba y Bellido-Pérez 2019; Leach y Allen 


\section{artnodes}

2017), y porque al aparato de poder le cuesta atajar una actividad iconoclasta que se esfuma tan pronto como es detectada.

Vita brevis, podría ser la divisa del meme, llamado como está a desaparecer en cuanto quedan atrás las circunstancias que lo motivaron o se ve superado por otros en un marco de fuerte competencia; advertía Marx que «el ciclo que describe la serie de metamorfosis experimentadas por toda mercancía se enreda de manera inextricable con los ciclos de otras mercancías» $(1975,136)$, y nada más aplicable al caso. Urgente, precario y efímero por definición, el meme habita una pura provisionalidad y todo afán conservacionista (Kurutz 2020), guiado por el principio de que «el valor de estos objetos digitales como fuente de información primaria para los investigadores en el futuro plantea retos para su conservación y preservación» (García y Martínez 2020, 897), podría estar desfigurando ese estatuto a poco que reparemos en que cualquier meme es solo una versión en nervioso tránsito hacia la siguiente. Si en manos de historiadores, museólogos y comisarios de arte «lo que originalmente era iconoclasia ha devenido iconofilia» (Groys 2011, 24), otro tanto puede decirse de estos radicales libres afectados como sin querer por el denominado mal de archivo (figura 5).

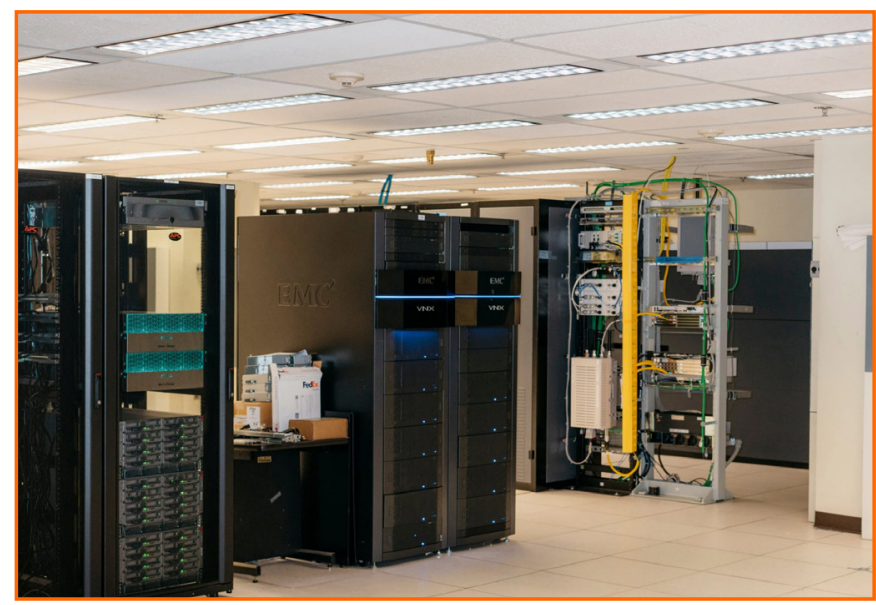

Figura 5. Servidor que aloja el archivo de material web de la Biblioteca del Congreso de EE.UU

Que la endoiconoclasia es un rasgo habitual en la creación digital al que la archivística intenta poner freno se evidencia también en aquellas manifestaciones del born-digital art que no fueron concebidas para perdurar y sin embargo, a causa de su relevancia aparente, están llamadas a serlo. En una entrevista al hilo de la integración museológica de su obra OSS/...., producida en 1998 bajo la forma seudoviralde un CD adjunto a la revista Mediamatic, Joan Heemskerk, de JODI, reconocía que «cuando nos pidieron que la pusiéramos en la colección dijimos que no, que se trata de la distribución de la obra, de las relaciones personales, no de algo que metes en el ordenador y se coloca en una exposición» (Laforet y Perrin 2013, 382). Para JOD resultaba problemático que $0 S S / . .$. acabase migrada y encapsu- lada en un formato inocuo y frío, y más aún tratándose de una obra sarcásticamente iconoclasta que en su forma genuina -el disco en cuestión no exhibía más que ese enigmático nombre-actuaba como un ejecutable que fingía arruinar el escritorio del ordenador donde se insertaba. Enfrentados a la fascinación tecnológica y a la ilusión de confort que suscitaban los nuevos dispositivos, ellos y muchos otros artistas se servían de las posibilidades de intervención que estos ofrecían para perturbar esa normalidad acogiéndose a los principios que en 1985, en plena eclosión de la informática de consumo, había formulado Vilém Flusser:

«El desafío es hacer imágenes que sean poco probables desde el punto de vista del programa de los aparatos [...]. Tal como están programados, los aparatos no sirven para producir imágenes informativas. Es preciso, entonces, utilizarlos contra sus programas. Es preciso luchar contra su automaticidad [...]. El gesto productor de imágenes se revela así como un gesto compuesto por dos fases. En la primera fase los aparatos son inventados y programados. En la segunda, los aparatos son invertidos contra su programa. La primera fase es ejecutada por científicos y técnicos; la segunda, por los productores de las imágenes propiamente dichos.» $(2015,46)$

Para los activistas digitales, sostiene Flusser, este «gesto desprogramador» $(2015,46)$ deviene la estrategia artística por antonomasia de igual forma que para las vanguardias históricas lo era arremeter contra toda convención y todo bienestar, de ahí que «el derecho a decir no se revela, en este contexto, como sinónimo de arte puro» $(2015,176)$. A la renovación de la máquina icónica inducida por la digitalización responde su contraparte iconoclasta cuestionando a las primeras de cambio sus principios operativos, algo bastante lógico si tomamos en cuenta que en el ámbito de los nuevos medios «los iconoclastas son los hiperfuturistas de la autenticidad y de la verdad alternativa» (Perniola 2011, 149). Quizá no haya mejor evidencia de esta pulsión política y ética que el browser art de la segunda mitad de los años noventa, con su característico experimentalismo y su fijación en un modelo que por entonces apenas acaba de nacer pero se hace ya acreedor de un rotundo así no: la interfaz de Internet. En efecto, para creadores como Matthew Fuller «el World Web Consortium, Netscape y Microsoft tienen visiones cerradas de lo que debería ser la web» (Weibel y Druckrey 2001, 276) y por ello su colectivo I/0/D proclama que «se acabó el diseño gráfico de papel pegado sobre el monitor» (Backspace s. f.) y le opone la peculiar dinámica de Web Stalker (1999), al tiempo que Mark Napier defiende la ferocidad de su Shredder 1.0 (imagen 6) con argumentos plenamente coincidentes: «El pensamiento actual del diseño web es el de la revista, el periódico, el libro o el catálogo [...]. Pero ¿qué pasa si estas instrucciones se interpretan de manera diferente a la prevista, quizá radicalmente diferente? [...]. Shredderpresenta esta estructura global como una pintura de acción caótica, irracional y estridente. Al alterar el código HTML antes de que el navegador lo lea, Shredder se apropia de los datos de la web, transformándolos en una web paralela. El contenido se convierte en abstracción. El texto se convierte en gráficos. La información se convierte en arte.» (Napier s. f.) 


\section{artnodes}

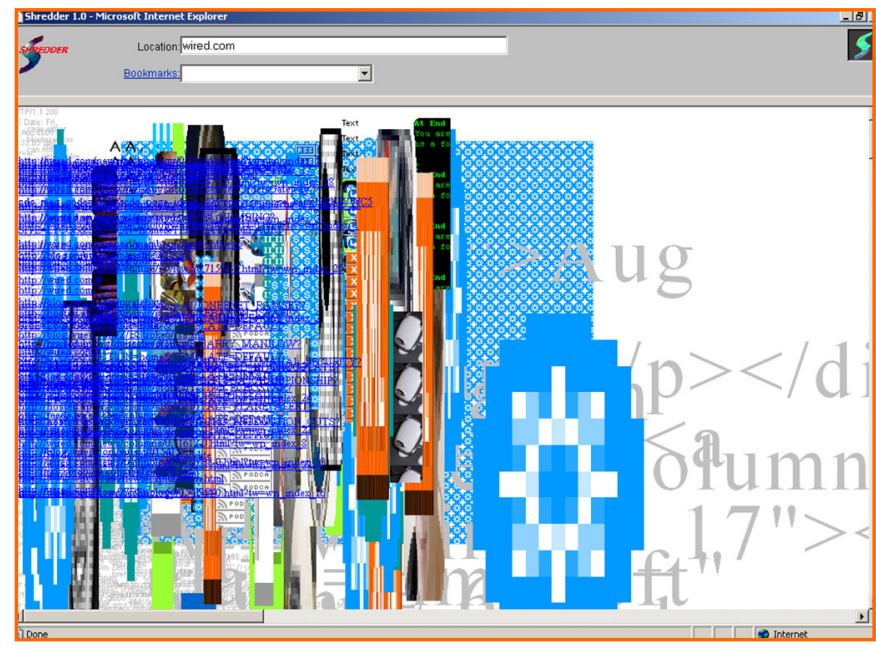

Figura 6. Mark Napier. Schredder 1.0 actuando con la web de Wired. 1998

En la misma línea se mueven muchas otras iniciativas de esos años, desde Wrong Browser (1999) de los propios JODI al tardío Glitchbrowser (2005) de Dimitri Lima, pasando por Reconnoitre (1999, figura 7), definido por sus creadores Gavin Baily y Tom Corby como un navegador que «se preocupa menos por la visualización coherente de información que por representar la navegación como una actividad de comportamiento» (Baily y Corby s. f.), o el celebrado Netomat (1999) de Maciej Wisniewski, que según él «tiene el aspecto de un antinavegador y muestra la anacrónica estructura de página de la web actual al no privilegiar la apariencia y el diseño», permitiendo con ello que «los datos no estén limitados por una página 0 un sitio web sino que floten libremente y sean independientes» (Weibel y Druckrey 2001, 81).

Salvajes 0 poéticos, fácticos 0 especulativos, los disruptive browsers de la época son máquinas iconoclastas en el sentido más literal de la expresión porque distorsionan, mutilan o neutralizan todo código que pretenda adoptar una forma visual al uso, y no deja de ser una especie de venganza sobrevenida que la obsolescencia de los

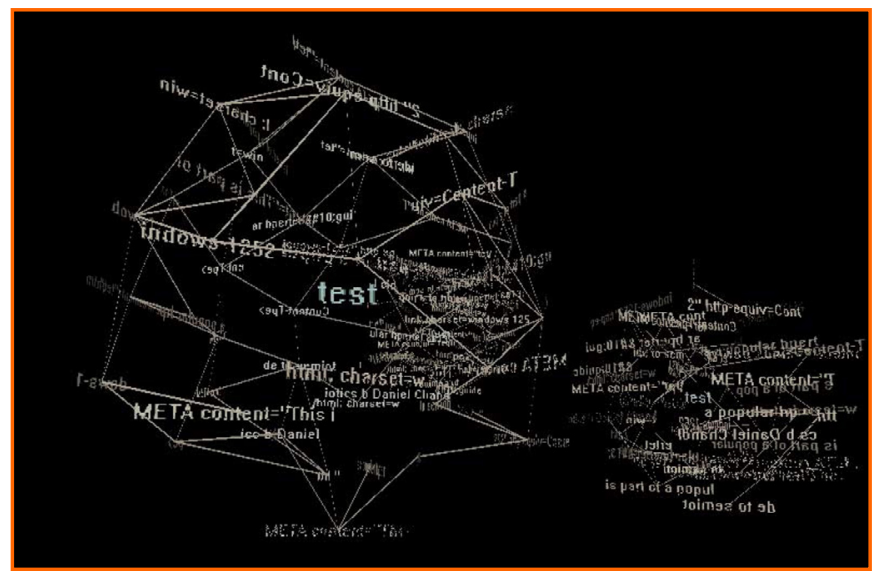

Figura 7. Gavin Baily y Tom Corby. Reconnoitre. 1997 navegadores, equipos y sistemas operativos en torno a los cuales se concibieron haya motivado que apenas si quede de ellos unos cuantos vídeos espectrales 0 esporádicas capturas de pantalla. Aunque en buena medida el browser art de los orígenes dejase su impronta en propuestas afines a plataformas como Artzilla 0 en la textura formal de un Jim Punk, lo cierto es que sus estrategias revulsivas acabarían devaluándose hacia un activismo de baja intensidad (Evan Roth y su China Channel) o un formalismo afable (Textfreebrowsing y Abstractbrowsing de Rafaël Rozendaal). Podría decirse que la distancia que separa el digital punk del internet ugly (Douglas 2014) y el hacking guerrillero del glitch impostado equivale aquí a la existente entre la iconoclasia reivindicativa y el goce estético, toda vez que «una imagen auténtica debería darse como una imagen crítica, una imagen en crisis, una imagen que critica la imagen -capaz, por lo tanto, de una eficacia teórica-» (Didi-Huberman 2006, 113), y no como un ornamento sin eco aparente.

\section{Visto y no visto}

Que la interfaz entonces sometida a crítica haya llegado a ser el estándar indiscutido que es hoy en día se debe ante todo a los agentes corporativos, ya provenientes de la época dorada de Internet, ya de reciente aparición, que lo administran casi en exclusiva. El modelo de gestión que despliegan estos operadores se basa en gran medida en estrategias que les permiten rehuir o neutralizar todo aquello que pueda resultar atentatorio contra sus intereses, de modo que también aquí la praxis iconoclasta cae del lado negativo y pasa de tener un sesgo reivindicativo a prestar sus servicios a un nuevo e implacable régimen de visibilidad. Lo que era actividad crítica hacia las imágenes deviene bloqueo y la violencia insurgente muta en neutralización, y esta paradójica retorsión del así no, afectada como está por regulaciones de calculada ambigüedad -se apela a materiales «que resulten apropiados para una audiencia diversa» (Instagram s. f.) para darles cauce o mantenerlos con vida visual-, permite evidenciar una vez más que «la censura precede, como fase inicial, a la iconoclasia» (Freedberg 2017, 59). Intervenir las imágenes se convierte en una táctica empresarial que afecta por igual a instantáneas vulgares y a obras artísticas, a la vida cotidiana y a la superestructura cultural, de modo que sortear esta máquina iconoclasta de corte moralizante que cuando no es regulada por tamices algorítmicos lo es por turcos mecánicos-detenerse en la ironía de la coincidencia terminológica está de más- ha acabado por convertirse en una de las operaciones con mayor empuje reivindicativo en la actualidad, en especial a manos de aquellos colectivos que ven su identidad gravemente comprometida (Olszanowski 2014; Tan 2017) y ansían que su expresión visual acabe llegando a donde debe llegar: a ese lugar de las imágenes (Belting 2007) que es la mirada de los demás. 


\section{artnodes}

https://artnodes.uoc.edu

La máquina iconoclasta en la era digital

En este constante toma y daca sucede que al deseo de libre circulación de unas imágenes puede seguirle el de frenar otras que pongan en entredicho el derecho a la propia invisibilidad. Al recelo que desde hace décadas despiertan los sistemas de videovigilancia públicos y privados se añade hoy la constante sospecha de monitorización de la imagen personal, bien sea directa, a través de las cámaras incorporadas a los dispositivos electrónicos, bien indirecta, mediante el control de las imágenes de cada cual existentes en la Red. Las labores de zapa para abortar estas prácticas son múltiples y pueden ir de la didáctica experimental de Hito Steyerl en How not to be seen: A fucking didactic educational.MOV file (2013) a las iniciativas de Adam Harvey para impedir la identificación del rostro mediante enmascaramientos (CV Dazzle, 2010) o patrones disuasorios (Hyperface, 2016), pasando por aportaciones de la comunidad científica (Sharif et al. 2016) o de los propios usuarios. Haciéndose eco de ese descontento, numerosos Estados despliegan una iconoclasia profiláctica que insta a la eliminación regular de los registros de los sistemas de circuito cerrado y ampara la potestad de la ciudadanía sobre su rastro digital, incluyendo el visual, en tanto las corporaciones se ven cada vez más presionadas para certificar la aplicación efectiva de ese derecho. Pese a todo, y dudando legítimamente de que así sea, los usuarios se ven seducidos cada tanto por instrumentos que prometen la caducidad inmediata de las imágenes -así Kaboom y sus secuelas recientes-e incluso su encriptación -así Crypstagram-, una oferta pueril si atendemos al hecho de que toda imagen digital es de por sí una clave numérica a la espera de una eventual epifanía.

Efectivamente, hoy más que nunca «el tratamiento de la imagen es una cuestión del dispositivo de visibilidad» (Rancière 2010, 103104), y en sus tránsitos entre unos y otros esa matriz numérica que la alberga sufre un desgaste que afecta a su carga icónica pero también a su condición ontológica. En palabras de Hito Steyerl, «la imagen pobre ha sido subida, descargada, compartida, reformateada y reeditada [...] es una bastarda ilícita de quinta generación de una imagen original [...] no solo está frecuentemente degradada hasta el punto de ser un borrón apresurado, es incluso dudoso que se la pueda llamar imagen» $(2014,34)$. Que este despojo imaginal siga circulando febrilmente de una pantalla a la siguiente sin que apenas importe su incesante pérdida de calidad solo puede explicarse porque funge como víctima propiciatoria en «la circulación en enjambre, la dispersión digital, las temporalidades fracturadas y flexibles» (Steyerl 2014, 48), es decir, como simple valencia en Ios flujos de intercambio social. Así como Thomas Ruff plasma en sus Jpegs (2004) este manoseo de la imagen que la aboca a la casi nada, así también otros artistas se centrarán en las paradojas de esta fantasmagoría -valgan como ejemplo los Seascapes (2016, figura 8) de Barry Stone, donde el código sustituye las sinuosidades del paisaje fotográfico que refiere- 0 como una latencia que exhibe ufanamente su opacidad. Viene al caso 2001100011 (2011, figura 9), de Claire L.

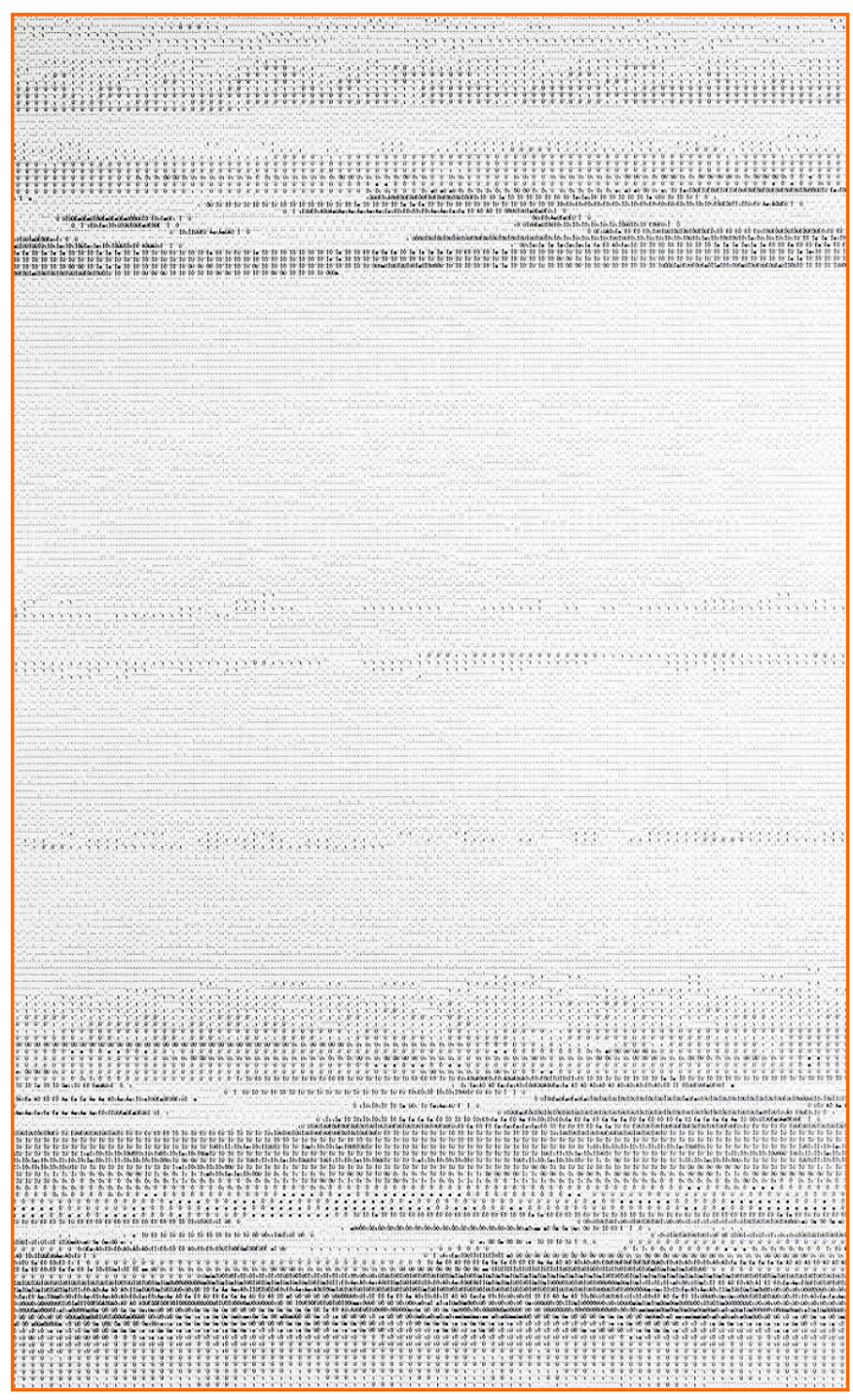

Figura 8. Barry Stone. 20150714-DSCF9296_3.txt, Bailey Island, Maine (seascape). 2016

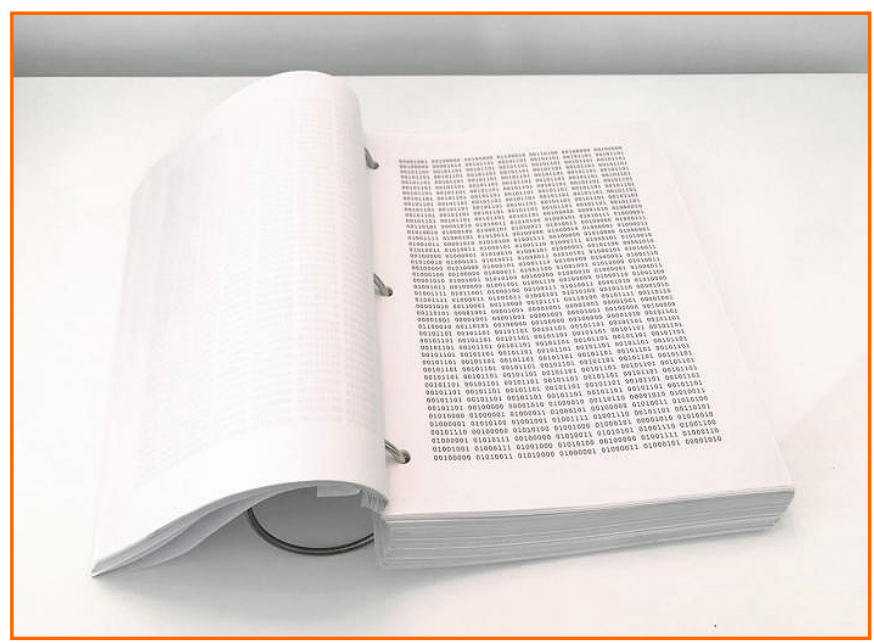

Figura 9. Claire Evans. 2001 100011. 2011 


\section{artnodes}

https://artnodes.uoc.edu

La máquina iconoclasta en la era digital

Evans, donde el film 2001: Una odisea del espacio deviene un rudo bloque de folios de código binario, pero también obras anteriores en el tiempo como Digitale partituren (1995, figura 10), donde Andreas Müller-Pohle hace lo propio al abstraer la de por sí abstracta Point de vue du Gras (1826, figura 11) de Nicéphore Niépce, primera imagen fotográfica de la que haya constancia.

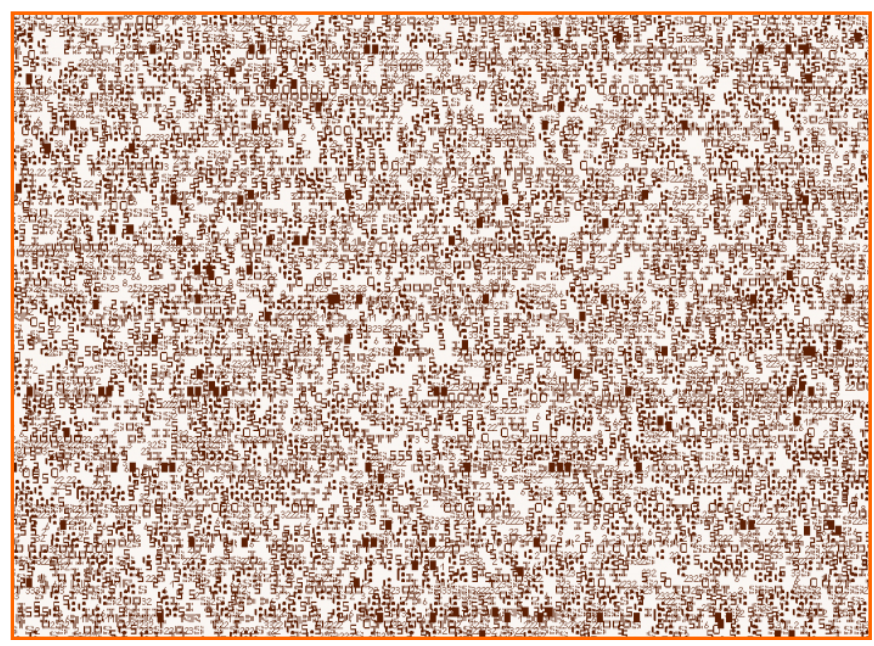

Figura 10. Andreas Müller-Pohle. Digitale partituren (detalle). 1995

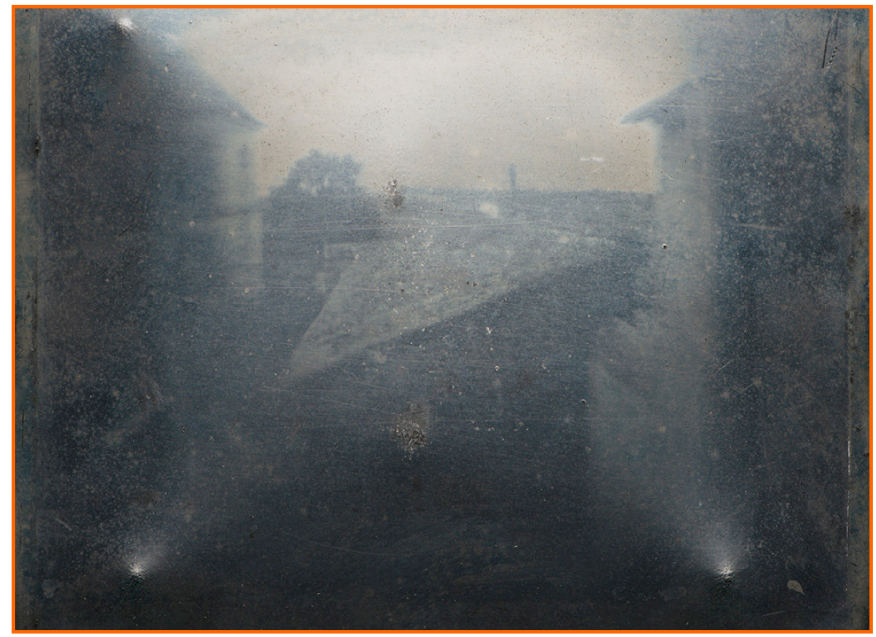

Figura 11. Nicéphore Niépce. Point de vue du Gras. 1826

A este énfasis en la trastienda de las imágenes se añade la acusación de banalidad que, a fuerza de clonarse y autorreferenciarse sin freno, recae sobre todas ellas, y no faltará quien detecte en la ingesta masiva de este material de saldo una insólita forma de iconoclasia:

«Consumimos imágenes preferentemente como falsos artificios técnicos para poder ignorar tanto mejor su pobreza semántica [...]. La idolatría se transforma, en este sentido, en una iconoclasia con el signo modificado. Ya que las imágenes están vacías, disfrutamos de la ficción con la que brillan.» (Belting 2012, 91-92)
Del tradicional culto a las imágenes, sostenido en la creencia en su vínculo orgánico con aquello que refieren, se pasa a un ceremonial cínico donde el valor en curso no es ya la excelencia sino una insustancialidad que el capitalismo de la atención, obcecado como está por el volumen global de imágenes y por los datos que llevan aparejados, refuerza de buen grado. Para Bruno Latour, de entre los modos iconoclastas este «amplio, popular e indestructible agnosticismo» $(2002,29)$ es el más desconcertante de todos porque la multitud de sus practicantes ni instiga ni actúa sino que se regodea en la degradación de las imágenes como quien asistiera a un naufragio que no le concerniese en absoluto (Blumenberg 1995). A la vista de las circunstancias, como fin de fiesta a esta celebración de la insignificancia tal vez solo reste reducir las imágenes a la más absoluta neutralidad, ya sea retomando la ferocidad vanguardista -en la estela de Guy Debord, Timm Ulrichs o Emilio Isgró, digamos-, ya mediante un iconicidio masivo o un envite aceleracionista que dé al traste con todo el sistema.

De forma cautelar, y sin llegar a estos extremos, hay quien aboga por restringir el contingente visual en circulación apelando a una economía de las imágenes que en último término favorezca su condensación y cierta recuperación del sentido perdido. La apuesta se entiende mejor si tomamos el término oikonomia en su acepción genuina, esto es, como «la ciencia y la técnica del orden y la subordinación de las partes a un todo» (Mondzain 2005, 40) 0 «una actividad de gestión que no está vinculada a otras reglas que no sean el ordenado funcionamiento de la casa» (Agamben 2008, 34), de modo que, así como se apela a la responsabilidad colectiva para frenar la degradación del planeta, así una óptima oikonomia de las imágenes vendría a paliar los desmanes de una iconocracia desaforada que evoca aquella hiperinflación visual del bizantinismo. Asumiendo que la administración de la casa icónica común debiera partir de un compromiso individual -manteniendo un estricto control personal del gasto icónico y de las emisiones visuales, por ejemplo-, iniciativas como la Camera restricta de Philipp Schmitt (2015, figuras 12 y 13) ensayan una propedéutica

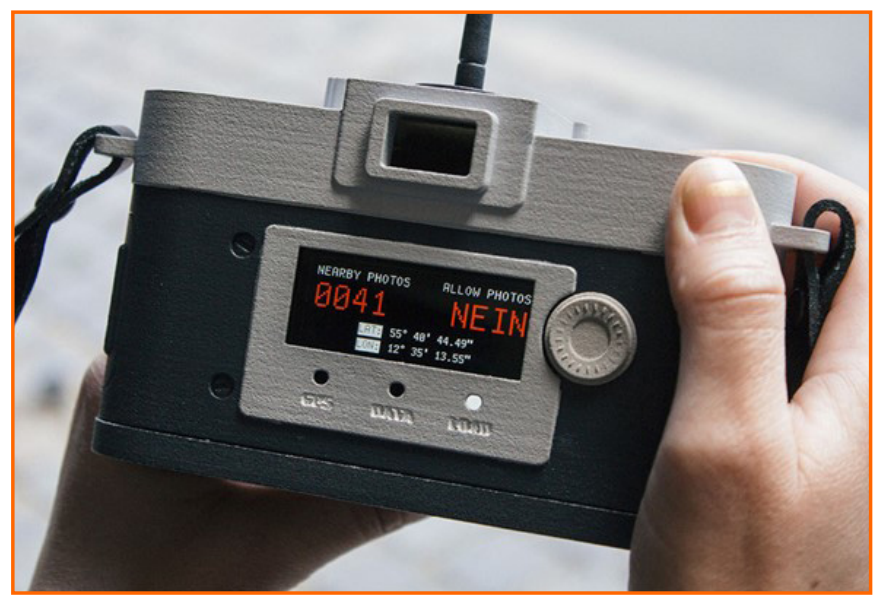

Figura 12. Philipp Schmitt. Camera restricta. 2015 


\section{artnodes}

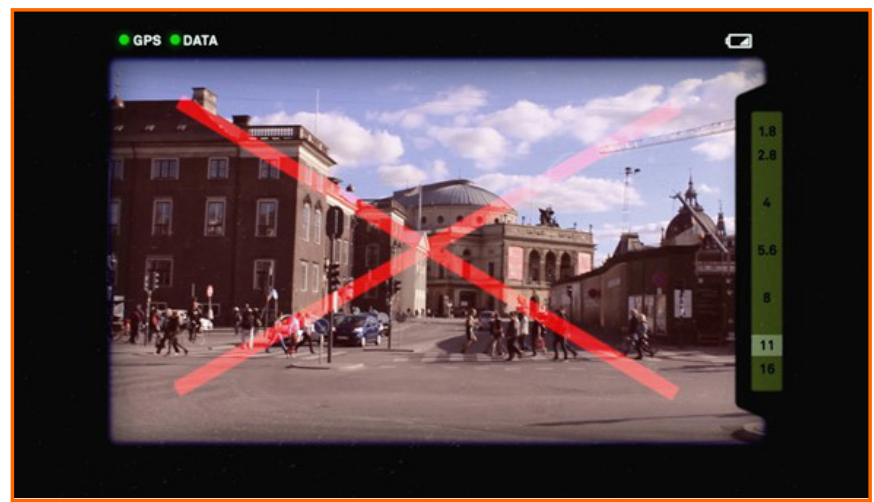

Figura 13. Philipp Schmitt. Camera restricta. 2015

de esa gestión de mínimos al impedir la toma de imágenes adocenadas -la cámara en cuestión geolocaliza al usuario y se bloquea cuando detecta en Internet un excesivo número de instantáneas tomadas ya en ese mismo lugar- en pro de un edénico ecosistema visual de escala mundial.

En buena medida, si Rafael Montañez Ortiz auguraba en su Manifiesto destructivista de 1962 que «el arte que utiliza los procesos destructivos purgará, pues así como da la muerte, dará la vida» $(1988,52)$, quizá este tipo de utillaje iconoclasta constituya hoy el tipo de contribución artística más afín a ese espíritu tras comprobarse que la iconoclasia performativa ha acabado alentando el espectáculo y el imperativo icónico que en principio aspiraba a combatir. Retomando el célebre para qué poetas en tiempos de penuria de Hölderlin cabe preguntarse qué necesidad hay de artistas en tiempos de abundancia visual, y aunque no sea fácil hallar una respuesta quizá pueda en parte ser esta: para promover un cuestionamiento, una mejora 0 una reformulación integral del ecosistema visual, siendo como son actantes cualificados, economistas de las imágenes a quienes asiste más que nunca la virtualidad depurativa de la máquina iconoclasta. Un mensaje nada nuevo, pensarán algunos, pero no por ello menos pertinente.

\section{Conclusiones}

Desde su origen mismo las imágenes han actuado como instrumentos al servicio de intenciones y cometidos de todo tipo y la actividad iconoclasta refuerza este hecho al emplearlas como un material en bruto que igual sirve a un fin que a su contrario, al afán creador que al nihilista, al ataque que a la defensa. No podría ser de otro modo, en realidad, si tenemos en cuenta que la fuerza motriz de la máquina iconoclasta se abastece de una corriente alterna donde el desprecio y la desidia 0 la violencia y la diversión constituyen oscilaciones de un mismo flujo energético. El momento actual es especialmente significativo en este sentido porque a la pervivencia de la iconoclasia tradicional, guiada ante todo por acciones de destrucción manifiesta, vienen a añadirse insólitos modelos: en un extremo, una política del cuidado que contra todo pronóstico conecta las instituciones culturales con las corporaciones digitales al neutralizar la imagen por estrechez de miras o por exceso de celo; en el otro, prácticas populares y artísticas capaces de desvelar el trasfondo de las imágenes 0 de contrarrestar la ejecutoria del poder -sea sancionado, tácito 0 difuso- con medios tan precarios como eficaces.

Aunque las páginas anteriores apenas si han dado para sondear algunas de esas prácticas, dejando fuera de su alcance un sinfín de estrategias relacionadas, por ejemplo, con el ámbito del arte interactivo, el del videoarte 0 el de los videojuegos, quizá hayan permitido al menos ponderar la utilidad del patrón iconoclasta a la hora de abrirse paso en una iconosfera tan enmarañada como las disposiciones, los hábitos y los intereses que orbitan a su alrededor. A fin de cuentas, la noción de máquina iconoclasta no ha sido aquí convocada con afán de exhaustividad sino con el fin de ayudar a pensar y dar que pensar: su marco competencial es únicamente ese. Advertía Furio Jesi que la noción de máquina mitológica puede dejar de ser «un modelo gnoseológico provisionalmente útil cuando nos dejamos hipnotizar por ella, es decir, cuando nos dejamos captar por su indudable fuerza fascinadora» $(1976,138)$, y otro tanto puede afirmarse de una formulación que tal vez pueda cautivar -la iconoclasia, en tanto forma inocua de violencia, luce bien- pero que se propone ante todo como un artefacto epistémico, no como una marca conceptual. Este artículo quisiera constituir una primera tentativa de ensayar su utilidad.

\section{Referencias bibliográficas}

Agamben, Giorgio. El Reino y la Gloria. Para una genealogía teológica de la economía y del gobierno. Homo sacer II, 2. Valencia: Pretextos, 2008.

Algaba, Cristina y Elena Bellido-Pérez. «Memes as an ideological tool: The stance of the Spanish online newspapers regarding the Catalan Referendum and Catalan Regional Elections 2017». Catalan Journal of Communication \& Cultural Studies 11, n. ${ }^{\circ} 2$ (2019): 265-287. DOl: htpp://10.1386/cjcs_00007_1.

Backspace. I/O/D. Browser2 book questionnaire. https://bak.spc. org/iod/B2_Quest.html.

Baily, Gavin y Tom Corby. Reconnoitre. http://www.reconnoitre. net/rec/index.php.

Baker, James E., Kelly A. Clancy y Benjamin Clancy. «Putin as gay icon? Memes as a tactic in Russian LGBT+ Activism». En Radzhana Buyantueva y Maryna Shevtsova (eds.). LGBTQ+ Activism in Central and Eastern Europe, 209-233. Nueva York: Palgrave MacMillan, 2020.

Bal, Mieke. Conceptos viajeros en las humanidades. Una guía de viaje. Murcia: CENDEAC, 2009. 
Belting, Hans. Antropología de la imagen. Buenos Aires: Katz, 2007. Blumenberg, Hans. Naufragio con espectador. Madrid: Visor, 1995. Blumenberg, Hans. Paradigmas para una metaforología. Madrid: Trotta, 2003.

Canetti, Elias. Masa y poder. Madrid: Alianza/Muchnik, 1983.

Davison, Patrick. «The language of Internet memes». En Michael Mandiberg (ed.). The social media reader, 120-134. Nueva York: New York University Press, 2012.

Dawkins, Richard. The selfish gene. Oxford: Oxford University Press, 1976.

Delgado, Manuel. Luces iconoclastas. Anticlericalismo, blasfemia y martirio de imágenes. Barcelona: Ariel, 2001.

Didi-Huberman, Georges. Lo que vemos, lo que nos mira. Buenos Aires: Manantial, 2006.

Douglas, Nick. «lt's supposed to look like shit: The Internet ugly aesthetic». Journal of Visual Culture 13, n. ${ }^{\circ} 3$ (2014): 314-339. DOI: https://doi.org/10.1177/1470412914544516.

Freedberg, David. El poder de las imágenes. Madrid: Cátedra, 2014.

Freedberg, David. Iconoclasia. Historia y psicología de la violencia contra las imágenes. Vitoria: Sans Soleil, 2017.

Gadamer, Hans-Georg. Verdad y método. Salamanca: Sígueme, 2001.

García, Fátima y Sara Martínez. «Strategies for preserving memes as artefacts of digital culture». Journal of Librarianship and Information Science 52, n. ${ }^{\circ} 3$ (2020): 895-904. D0I: https:// doi.org/10.1177/0961000619882070.

Groys, Boris. «El curador como iconoclasta». Criterios, n. ${ }^{0} 2$ (2011): 23-34. http://19bienal.fundacionpaiz.org.gt/wp-content/ uploads/2014/02/CURADOR-ICONOCLASTA-BGROYS-02.pdf.

Instagram. Normas comunitarias. https://help.instagram.com/47 7434105621119?helpref=page_content.

Jesi, Furio. Mito. Barcelona: Labor, 1976.

Kurutz, Steven. «Digital hoarders corral the Web». New York Times, 12 de abril de 2020. https://www.nytimes.com/2020/04/07/style/internetarchive-librarycongress.html?action=click\&module=Editors $\% 20$ Picks\&pgtype=Homepage

Laforet, Anne y Valérie Perrin. «OSS/.... An interview with JODI (Joan Heemskerk and Dirk Paesmans)». En Bernard Serexhe (ed.). Preservation of digital art: Theory and practice, 379-382. Karlsruhe: ZKM/Ambra, 2013.

Latour, Bruno y Peter Weibel. Iconoclash. Beyond the image wars in science, religion and art. Karlsruhe: ZKM/MIT Press, 2002.

Leach, Colin W. y Aerielle M. Allen. «The social psychology of the Black Lives Matter meme and movement». Current Direc- tions in Psychological Science 26, n. ${ }^{\circ} 6$ (2017): 543-547. D0I: https://doi.org/10.1177/0963721417719319.

Maffesoli, Michel. Ensayos sobre la violencia banal y fundadora. Buenos Aires: Dedalus, 2012.

Marx, Karl. El capital. Crítica de la economía política (Libro primero: El proceso de producción del capital). Madrid: Siglo XXI, 1975.

Mondzain, Marie-José. Image, Icon, Economy. The byzantine origins of the contemporary imaginary. Stanford: Stanford University Press, 2005.

Montañez Ortiz, Rafael. «Destructivism: A manifesto». En $A A$. VV. Rafael Montañez Ortiz: Years of the warrior 1960, years of the pysche 1988. Nueva York: El Museo del Barrio, 1988.

Moreno-Almeida, Cristina. «Memes as snapshots of participation: The role of digital amateur activists in authoritarian regimes». New Media \& Society, n. 0 (2020): 1-22. D0I: https://doi. org/10.1177/1461444820912722

Napier, Mark. Schredder 1.0. http://www.potatoland.org/shredder/ about.html.

Olszanowski, Magdalena. «Feminist self-imaging and Instagram: Tactics of circumventing censorship». Visual Communication Quarterly 21, n. ${ }^{0} 2$ (2014): 83-95. D0I: https://doi.org/10.10 80/15551393.2014.928154.

Perniola, Mario. La sociedad de los simulacros. Buenos Aires: Amorrortu, 2011.

Rancière, Jacques. El espectador emancipado. Castellón: Ellago, 2010.

Sharif, Mahmood, Sruti Bhagavatula, Lujo Bauer y Michael K. Reiter. «Accessorize to a crime: real and stealthy attacks on state-of-the-art face recognition». CCS'16: Proceedings of the 2016 ACM SIGSAC Conference on Computer and Communications Security. Viena, Austria (2016): 1.528-1.540. https:// www.cs.cmu.edu/ sbhagava/papers/face-rec-ccs16.pdf.

Steyerl, Hito. Los condenados de la pantalla. Buenos Aires: Caja Negra, 2014.

Tan, Jia. «Digital masquerading: Feminist media activism in China». Crime Media Culture 13, n. ${ }^{0} 2$ (2017): 171-186. D0I: https:// doi.org/10.1177/1741659017710063.

Weibel, Peter y Timothy Druckrey. Net condition. Art and global media. Karlsruhe: ZKM/Steirischer Herbst/MIT Press, 2001.

Wiggins, Bradley E. y Bret G. Bowers. «Memes as genre: A structurational analysis of the memescape». New Media \& Society 17, n. ${ }^{0} 11$ (2015): 1.886-1.906. https://www.researchgate.net/ publication/288811719_Memes_as_genre_A_structural_analysis_of_the_memescape. 


\section{artnodes}

https://artnodes.uoc.edu

La máquina iconoclasta en la era digital

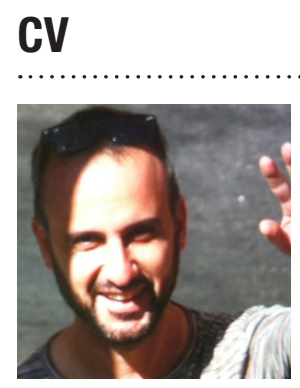

José María de Luelmo Jareño

Universitat Politècnica de València (España)

Facultat de Belles Arts

jolueja@pin.upv.es

Profesor titular de la Universitat Politècnica de València (España), donde imparte clases en el Máster Oficial en Artes Visuales y Multimedia y en el Grado en Diseño y Tecnologías Creativas. Se doctoró en Bellas Artes en dicha universidad y prepara actualmente su doctorado en Filosofía por la Universitat de València. Sus investigaciones sobre la imagen, de muy amplio espectro, han formado parte de numerosos congresos y han sido publicadas en revistas científicas de España, México, Chile, Colombia y Brasil, en revistas culturales como Archipiélago, Pasajes, Lápizy Lars, en un par de monografías, y en diversas obras colectivas. Los resultados de su práctica artística han llevado a una veintena de exposiciones individuales y a integrar más de un centenar de carácter colectivo. 